\title{
INEFICIÊNCIA, CORRUPÇÃO E DESIGUALDADE: TRÊS MALES A SEREM SUPERADOS NO CAMINHO DO DESENVOLVIMENTO DO BRASIL
}

\author{
Fernando Pereira da Silva ${ }^{1}$
}

Resumo: Este estudo analisa três males apontados, frequentemente, por diversos analistas políticos e econômicos como empecilhos para o desenvolvimento brasileiro: ineficiência, corrupção e desigualdade. A adoção de medidas como gestão transparente; melhor utilização do fundo público, em favor dos mais pobres; distribuição equânime dos tributos e outras políticas públicas serão aqui tratadas. O Brasil precisa caminhar para o almejado desenvolvimento e se defende que esse caminho passa pela melhor distribuição de renda, bem como gestão eficiente, transparente e honesta dos limitados recursos públicos.

Palavras-chave: Ineficiência; corrupção, desigualdade, políticas públicas; desenvolvimento.

\section{INEFFICIENCY, CORRUPTION AND INEQUALITY: THREE MALES TO BE OVERLIVED ON THE PATH OF DEVELOPMENT IN BRAZIL}

\begin{abstract}
This study analyzes three evils often pointed out by several political and economic analysts as obstacles to Brazilian development: inefficiency, corruption and inequality. The adoption of measures such as transparent management; better use of the public fund in favor of the poorest; equitable distribution of taxes and other public policies will be dealt with here. Brazil needs to move towards the desired development and it is defended that this path goes through the best distribution of income, as well as efficient, transparent and honest management of the limited public resources.
\end{abstract}

Keywords: Inefficiency; corruption, inequality, public policies; development.

\footnotetext{
${ }^{1}$ Mestrando em Direito pela UNIRIO; Especialista em Advocacia Pública pela UERJ; Especialista em Direito Ambiental e Sustentabilidade pela FGV-RIO; e Especialista em Direito Tributário pela FGV-RIO. Tem experiência na área de Direito Público, com ênfase em Direito Administrativo, Militar, Ambiental e Penal (Segurança Pública).
} 


\section{INTRODUÇÃO}

O presente trabalho, de cunho exploratório, pretende analisar sobre a importância de se implementar políticas públicas com o objetivo de mitigar a ineficiência, corrupção e desigualdade no Brasil.

A metodologia utilizada foi a revisão bibliográfica, na qual foram utilizados livros e artigos científicos acerca das temáticas abordadas, bem como a análise documental de pesquisas sobre os problemas brasileiros.

A hipótese principal é que os males objetos deste estudo precisam ser combatidos simultaneamente para que se possa colher melhores resultados no que tange aos indicadores sociais e ao desenvolvimento do Brasil.

Dessa forma, defende-se que o administrador público não só deve ser honesto, mas também que a gestão dos recursos seja realizada com responsabilidade, priorizando o essencial, buscando maximizar vantagens ao cidadão. A aplicação do dinheiro público pelo gestor deve também favorecer aos mais pobres, por meio de políticas públicas que diminuam a extrema desigualdade social vigente no Brasil, o que representa o desejo do povo brasileiro expresso na Constituição Federal de 1988.

A sociedade brasileira vem amadurecendo, de modo que não basta um administrador honesto, porém incompetente; tampouco, o desonesto com fama de competente - conhecido antigamente como "rouba, mas faz" - corresponde atualmente aos anseios dos cidadãos. Precisa-se de gestores probos e eficientes, que saibam ser zelosos com o limitado dinheiro publico.

Ao mesmo tempo, é necessário um resgate social para se reduzir as desigualdades no Brasil. Favorecer aos mais pobres por meio de políticas públicas específicas de redistribuição de renda, incidência maior de tributos no patrimônio e renda, em detrimento do consumo; o uso do fundo público para o financiamento de uma educação de qualidade (principalmente nos níveis fundamental e médio); bem como de outras políticas sociais, com a finalidade de possibilitar acesso mais isonômico aos bens e serviços, sejam privados, sejam públicos são medidas imprescindíveis para mitigar as desigualdades e favorecer o desenvolvimento econômico e social do Brasil.

É preciso lembrar que são objetivos fundamentais do Brasil, expresso no art. $3^{\circ}$ da Constituição Federal: construir uma sociedade livre, justa e solidária; garantir o desenvolvimento nacional; erradicar a pobreza e a marginalização e reduzir as desigualdades 
sociais e regionais; promover o bem de todos, sem preconceitos de origem, raça, sexo, cor, idade e quaisquer outras formas de discriminação. Para que isso se concretize e não seja letra morta na Constituição é preciso que se combata a ineficiência, a corrupção e a desigualdade, como se observará neste estudo.

\section{GESTÃO EFICIENTE E PROBA COMO DIREITO FUNDAMENTAL}

Segundo DA SILVA (2005, p. 35) fundamento significa aquilo sobre o qual repousa certa ordenação ou conjunto de conhecimento, aquilo que dá a alguma coisa sua existência ou sua razão de ser, aquilo que legitima a existência de alguma coisa. Continua o ilustre professor ao ensinar que fundamento pode significar também o elemento primordial de um ser, isto é, que deve merecer tratamento prioritário. A Constituição de 1988 estabelece no art. 5:

Todos são iguais perante a lei, sem distinção de qualquer natureza, garantindo-se aos brasileiros e aos estrangeiros residentes no país a inviolabilidade do direito à vida, à liberdade, à igualdade, à segurança e à propriedade, nos termos seguintes.

Vale lembrar que, baseados na concepção francesa de liberdade, igualdade e fraternidade, a doutrina jurídica brasileira, de modo geral, classifica os direitos fundamentais em gerações ou dimensões: $1^{\mathrm{a}}$ Geração (Dimensão) - ligados à liberdade; $2^{\mathrm{a}}$ Geração (Dimensão) - à igualdade; e $3^{\mathrm{a}}$ Geração (Dimensão) - à fraternidade. Os direitos ligados à democracia, como o pluralismo, informação, participação, etc., costumam ser considerados como direitos fundamentais de $4^{\mathrm{a}}$ dimensão e a paz como $5^{\mathrm{a}}$ dimensão (BONAVIDES, 2016). Ainda, cabe registro que DA SILVA (1996, p. 179 e 180) atribui aos direitos fundamentais algumas características: historicidade, imprescritibilidade, inalienabilidade e irrenunciabilidade.

$\mathrm{Na}$ prática, para tornar real os direitos fundamentais, garantir a cidadania e os direitos expressos na Constituição brasileira vigente são necessárias políticas públicas cujo emprego do dinheiro público ocorra com eficiência e com probidade.

Política pública é um conjunto de decisões inter-relacionadas - tomadas por um ator ou grupo de atores políticos - que se referem à seleção de objetivos e dos meios necessários a alcançá-los, no âmbito de uma situação especificada em que o alvo dessas decisões estaria, em princípio ao alcance dos mesmos atores (Willian Jenkins apud HEIDEMANN, 2014, p. 31). 
Portanto, política pública é a ação governamental com o objetivo de influenciar, alterar, regular o comportamento individual ou coletivo. A formulação de políticas públicas constituise no estágio em que governos traduzem seus propósitos e plataformas eleitorais em ações, que produzirão resultados ou modificações na sociedade (SOUZA, 2007, p. 69).

Outrossim, para que as políticas públicas alcancem os objetivos traçados é preciso que o dinheiro público seja empregado com eficiência e lisura. Vale salientar as observações de Lobo Torres (2008, p. 298), que trata desenvolvimento econômico:

\footnotetext{
"Em nome do crescimento não se pode postergar a redistribuição de rendas, nem ofender os direitos humanos, nem atentar contra o meio ambiente, nem justificar a corrupção dos políticos.

$\cdots$

O princípio do desenvolvimento econômico não é um fim em si mesmo, mas deve afinar com o desenvolvimento humano, pois a qualidade da vida humana é que constitui um fim".
}

O citado autor expõe a necessidade de que o crescimento econômico esteja aliado ao desenvolvimento humano. Esse entendimento se adéqua ao texto constitucional que prevê os direitos fundamentais. Com efeito, é inadmissível sejam gasto dinheiro com aquilo que não é primordial como, por exemplo, prédios públicos luxuosos, enquanto uma ampla margem da população vê seus direitos constitucionais básicos flagrantemente negados. Leciona ainda TORRES (2008, p. 135): “A lei orçamentária serve de instrumento para afirmação da liberdade, para a consecução de justiça e para a garantia e segurança dos direitos fundamentais".

Por oportuno, observa-se no Brasil ainda condições precárias de saúde e educação a que as camadas mais pobres da população estão submetidas, são vários os exemplos: falta de serviços de saúde básicos (profiláticos e ambulatoriais); crianças em idade escolar, sem acesso à rede pública de ensino; parcela dos estudantes regularmente matriculadas não dispõem de infraestrutura para deslocamentos - tais condições são intensificadas nas Regiões norte, nordeste e no interior do Brasil. Como se vê, alguns dos direitos fundamentais ainda são constantemente desrespeitados, o que demonstra que, apesar do texto constitucional, a prioridade aos direitos fundamentais está longe de ser concretamente implementada no país.

FIGUEIREDO (1986, p. 114) observa sobre avaliação de políticas públicas sociais e a importância de resultados satisfatórios para a população de tais políticas:

Isto posto, o uso de critérios de eficiência para aferição do sucesso de políticas sociais não deve ficar restrito à dimensão instrumental, econômica. Tem-se que introduzir aí um nível de satisfação da população, pelo menos da população-alvo. Em uma palavra, 
que políticas públicas sejam instrumentalmente eficientes. Elas devem ser também politicamente eficientes.

Ressalta-se que o desperdício do dinheiro público, seja por corrupção, seja por ineficiência, em detrimento do custeio de políticas públicas de caráter fundamental como saneamento básico, saúde e educação repercutem negativamente contra a classe política. Pesquisas de opinião identificam tal tendência: a ONG Transparência Internacional de 2013 mostrou que $81 \%$ dos brasileiros consideravam os partidos corruptos, $72 \%$ tinham a mesma opinião sobre o Congresso, $70 \%$ sobre a polícia, e 50\% sobre o judiciário. As melhores imagens no que se refere à corrupção eram a da Igreja (31\%) e a dos militares (30\%), como aponta CARVALHO (2015, p. 235). Cumpre destacar que estes resultados não são isolados, repetindose o mesmo quadro reiteradamente nas pesquisas de opinião pública, o que demonstra a imagem ruim que a população brasileira tem em geral de seus representantes e instituições.

O saudoso professor MOREIRA NETO (2007, p. 51) destaca que a sociedade vem cobrando moralidade de seus representantes:

\footnotetext{
Moralidade tem sido cada vez mais cobrada dos parlamentares, dos juízes e dos administradores, na medida em que aumentam as decepções populares com a conduta de seus dirigentes. O descrédito dos políticos, como não poderia deixar de ocorrer, se tem comunicado as próprias instituições, abalando-as profundamente nos seus alicerces, tantas vezes tão laboriosamente plantadas pelos povos.

Em nosso país, essa crise é grande e necessita ser superada, até como condição fundamental para a retomada da governabilidade e do desenvolvimento. A preocupação com a moralidade é reclamo público, presente no povo, nos meios de comunicação e, é de se esperar, com frutífera repercussão na consciência e na ação dos homens públicos e dos profissionais de direito.
}

Dessa forma, é imprescindível que administrador preste contas, adote medidas de transparentes, seja responsável, enfim, não governe às escondidas, mas sim às claras como se cada ato seu fosse passível de questionamento e fiscalização.

O dever de boa administração exige uma relação íntima da eficiência, moralidade, responsabilidade e razoabilidade na avaliação e, principalmente, no emprego dos recursos públicos. O controle, planejamento e transparência são requisitos essenciais para o sucesso das políticas públicas governamentais.

Assim, verifica-se que a ação política dos governos expressa-se de dois modos, no campo econômico: a) intervindo diretamente na economia, seja na provisão de serviços públicos como saúde, educação, infraestrutura, saneamento básico, inclusive, se valendo de estatais para implementar políticas públicas de desenvolvimento; b) reguladora, por meio de 
leis que direcionem a ordem política e às iniciativas econômicas; participação direta na economia.

Cumpre esclarecer, embora haja quem ainda acredita entusiasticamente no livre mercado, que se compartilha nesse estudo o entendimento de Joseph Stinglitz, detentor do prêmio Nobel de Economia, que defende: “a noção de livre mercado é um mito. Todos os mercados são moldados por leis e regulações, mas infelizmente nossas leis e regulações são feitas para criar mais desigualdade e menos oportunidades" (Revista Time, 11-06-2012 apud HEIDEMANN, 2014, p. 29). No caso brasileiro, há farta legislação que buscam direcionar condutas para práticas consideradas benéficas ao país.

A lei de acesso à informação (Lei no 12527/11), anticorrupção (Lei n ${ }^{\circ}$ 12.846/13), improbidade (Lei no 8.429/92), a processo administrativo (Lei no 9.784/99), ação popular (Lei $\left.\mathrm{n}^{\mathrm{o}} 4.717 / 65\right)$ e outras têm a finalidade de assegurar maior transparência e atribuir responsabilidade aos administradores públicos.

Vale frisar ainda as leis que tratam de planejamento por parte do Estado das quais são exemplos a lei de licitações (Lei ${ }^{\circ}$ 8.666/93), lei de responsabilidade fiscal (LC $n^{\circ}$ 101/00) e as de planejamento orçamentário: o Plano Plurianual (PPA); Lei de Diretrizes Orçamentárias (LDO); Lei de Orçamento Anual (o Orçamento Geral da União, que engloba o Orçamento Fiscal, o Orçamento Monetário, o Orçamento das Empresas Estatais e o Orçamento da Previdência Social) e a Lei 4320/64.

Outrossim, no que tange ao planejamento orçamentário TORRES (2008, p. 63) ensina:

Em resumo, torna-se preciso e urgente colocar um paradeiro na corrupção na feitura
e execução do orçamento. Necessário também que se repense a questão do orçamento
à luz dos princípios éticos, a fim de que se acabe com o desperdício de dinheiro
público e se promova melhor a distribuição de rendas e mais justa alocação de
recursos.

TORRES (2008, p. 61) ainda cita como exemplo de falta de ética orçamentária decisão do judiciário - Supremo Tribunal Federal - que reconhece imunidades independente de as escolas garantirem matrículas gratuitas para alunos pobres; ou hospitais reservarem leitos para indigentes. Segundo tal decisão basta tão somente que se defina como entidade sem fins lucrativos para usufruírem de benefício fiscal (imunidade), logo, a filantropia seria ficcional e desconsideraria a demonstração real de que essa entidades não possuiriam fins lucrativos e prestavam de fato serviços sociais relevantes. Esse reconhecimento de imunidade equivaleria a 
uma subvenção social, resultando no empobrecimento do Estado e o enriquecimento das entidades.

Ressalta-se que, por melhor que seja, não há lei infalível diante da criatividade humana. Desse modo, acredita-se que os mecanismos de controle devem constantemente ser aperfeiçoados, de modo a coibir práticas delitivas dos agentes públicos. Uma sociedade que não consegue fornecer saneamento básico, saúde e educação para todos os seus cidadãos não pode tolerar desvios de recursos públicos, seja para financiar privilégios, seja para a corrupção.

Destaca-se que iniciativas legais supracitadas não excluem, pelo contrário, fortalecem o entendimento de que o cidadão deve participar da fiscalização do Estado. Defende-se aqui a participação das pessoas como protagonistas da transformação social brasileira, não uma cidadania passiva. Aliás, entende-se que sem essa participação os avanços serão comedidos e lentos, caso ocorram, como exemplificam as histórias brasileira e mundial ao retratar que as grandes modificações decorreram de mobilização popular. Normalmente, as dificuldades se ampliam sem pressão da sociedade organizada e como diz o poeta em verso que se acredita não sair de moda: "quem sabe faz a hora, não espera acontecer".

\subsection{Princípios de uma Boa Administração Pública}

O Banco Mundial sugere (WORLD BANK, 2007 apud NARDES et al, 2016, p. 182) como princípios da boa governança os seguintes: legitimidade, equidade, responsabilidade, eficiência, probidade, transparência e prestação de contas. Desse modo, a legitimidade está associada ao Estado democrático de direito e ao interesse público e bem comum; a equidade, a garantia das condições para que todos tenham acesso ao exercício de seus direito civis; a responsabilidade, o zelo dos agentes com a ordem social; a eficiência, fazer com qualidade no menor custo possível; a probidade, demonstrar honestidade e zelo ao utilizar, arrecadar, gerenciar e administrar bens e valores públicos; a transparência, possibilitar o acesso das informações relativas à organização pública; a prestação de contas, associa-se a permissão do controle social, de forma que sejam verificáveis e auditáveis e as contas.

Para se administrar bem algo é preciso controle. O controle da administração pública tem como finalidades a garantia dos direitos individuais, a proteção dos interesses públicos e dos direitos coletivos. Para isso, é preciso implementar medidas para a melhoria da atividade 
administrativa, de modo a defender o patrimônio público, prevenindo e combatendo à corrupção, bem como promovendo a adequada aplicação de recursos.

A Constituição Financeira inscrita no texto constitucional de 1988 é elaborada neste contexto de busca de maior controle e equilíbrio dos gastos públicos, segundo BERCOVICI (2006, p.63)

Por sua vez, é preciso tecer algumas considerações sobre governança pública que é a capacidade que os governos têm de avaliar, direcionar e monitorar a gestão de suas políticas ou serviços para atender às demandas da população, utilizando-se de um conjunto de instrumentos e ferramentas adequadas (NARDES et al, 2016, p. 177).

Já para Denhart (2012, p. 269-75 apud HEIDEMANN, 2014, p. 35), o processo de governança se refere ao modo pelo qual são tomadas decisões na sociedade e ao modo como os cidadãos e grupos interagem na formulação dos propósitos públicos e na implementação das políticas públicas.

Outrossim, expõe-se à seguir de forma sucinta, relação de ferramentas de governança que permitem controle das políticas públicas, segundo NARDES et al. (2016, p. 184):

\footnotetext{
- Especificar o que se espera do "agente" e aquilo que deverá ser entregue;

- Estabelecer missão, objetivos, indicadores, metas e alocação de recursos;

- Estabelecer cronograma de entrega de resultados para viabilizar acompanhamento e correção de possíveis desvios;

- Definir códigos de conduta;

- Determinar profissionais capacitados e independentes para avaliar a consistência das informações e dos resultados;

- Implantar sistemas de controle externo e interno, de forma a verificar se as normas, informações e a ações estão alinhadas com o projeto definido;

- Gerir riscos que consiste em planejar, organiza, dirigir e controlar os recursos da organização para minimizar os efeitos dos riscos no menor patamar possível;

- Estabelecer formas de participação nas tomadas de decisões relevantes; e

- Materializar a transparência: estabelecer de que forma os resultados serão publicados ou disponibilizados.
}

Vale citar ainda que NARDES et al. (2016, p. 188) destaca quatro passos para a melhoria de processos e resultados organizacionais, com foco na melhoria da relação custo e beneficio: planejar, executar, controlar e agir (corrigir os erros).

Com efeito, medidas de boa governança permitem avaliar a qualidade da atuação dos gestores, em função de comparar aquilo que foi planejado com os resultados efetivamente apresentados. 


\section{CORRUPÇÃO E ÉTICA}

A corrupção é amplamente difundida como um problema grave brasileiro. Diariamente, são noticiados casos de corrupção envolvendo autoridades brasileiras, cujas condutas diferem radicalmente daquilo que se almeja dos representantes governamentais.

No Senado Federal do total de 81, 45 senadores já foram condenados ou estão sendo investigados, por uma ofensa grave - os crimes incluem lavagem de capitais, o desfalque e a compra de votos. Na Câmara de Deputados, que já, 273 dos 513 membros estão sendo investigados ou já foram condenados, de acordo com Transparência do Brasil, conforme reportagem denominada: "More than half the lawmakers impeaching Brazil's president have been either convicted or investigated themselves".

Registre-se que há entendimento de que os representantes são reflexos da sociedade brasileira que seria eminentemente corrupta e tal corrupção se manifestaria com atos como: jogar lixo no chão, colar na prova, oferecer dinheiro em troca de algum benefício - todos, comportamentos que podem ser facilmente percebidos em nosso dia a dia, quase como se fossem situações corriqueiras e típicas da cultura brasileira. Por esse entendimento, o Brasil precisaria educar e instruir sua população para que passasse a rejeitar esses comportamentos antiéticos, superando com isso essa cultura arraigada na sociedade brasileira da esperteza.

Outrossim, vale lembrar que a prolatada desonestidade da população brasileira, não é exclusividade dos pobres, embora a esses seja frequentemente atribuída como se fosse atrelada a condição social. Empresários brasileiros prometem e não cumprem; inserem valores na conta, que o consumidor não pediu; deixam deliberadamente de prestar informações, com objetivo de vender produtos e aumentar lucros; sonegam tributos; se recusam a pagar os direitos trabalhistas que o empregado faz jus; vendem serviços e depois alegam os variados motivos para não cumprir o contatado; desrespeitam os consumidores, evidenciado pelas repetidas vezes que encabeçam as listas de reclamações no Brasil e sem reprenda compatível que os motive a modificar suas condutas, revendem em seus comércios produtos oriundos do crime e outros. São esses mesmos, que chamam de desonesto o cidadão pobre brasileiro e os políticos.

Por sua vez, merece destaque os problemas que a corrupção ocasiona, principalmente os relativos à implementação de políticas públicas sociais, conforme observa GARCIA (2008, p. 21) sobre corrupção:

As políticas públicas, ademais, são sensivelmente atingidas pela evasão fiscal, que consubstancia uma das faces da corrupção. Com a diminuição da receita tributária,

Rev. de Direito Administrativo e Gestão Pública | e-ISSN: 2526-0073 | Porto Alegre | v. 4 | n. 2 | p. 117 - 136 | Jul/Dez. 2018 
em especial daquela originária das classes mais abastadas, diminui a redistribuição de renda às classes menos favorecidas e aumenta a injustiça social.

A Convenção de Arrussha sobre Cooperação e Integridade Aduaneira, celebrada em Tanzânia, em 07 de julho de 1993, que trata de corrupção na área aduaneira, recomenda, para fins de se evitar a corrupção dos servidores públicos: a rotatividade entre servidores; a existência de critérios rígidos e objetivos de seleção; a redução de esfera de discricionariedade de tais agentes; o pagamento de remuneração compatível com a importância do cargo e a existência de mecanismos efetivos de controle, em especial na órbita disciplinar, conforme observa GARCIA (2008, p. 25).

Com efeito, elucida-se que diferentemente daqueles que defendem que a corrupção tenha aumentado excepcionalmente no Brasil, entende-se que os mecanismos de apuração nunca estiveram tão eficientes, como nos dias atuais. Os mecanismos de transparência põem à luz aquilo que anteriormente era escondido ou simplesmente se desconhecia. O histórico brasileiro aponta que a punição também se aproximou de pessoas cujo poder e dinheiro, até passado recente, não permitia a investigação, o que demonstra avanços no combate a corrupção.

Por oportuno, é preciso que nesse caminho de aperfeiçoamento do processo de investigação, das condutas consideradas corruptas, reconheçam-se as atuações meritosas e se coíba excessos. Portanto, são necessários ajustes observando-se os direitos fundamentais e a legislação em vigor que dispõe sobre o abuso de autoridade. Aliás, tais excessos são passíveis de ocorrer numa democracia, no afã de se obter resultados efetivos, contudo, devem ser coibidos. Registre-se, no entanto, o Brasil não deve retroceder no combate a corrupção, visto que, embora não seja a única causa, prejudica o acesso da população mais pobre as políticas sociais e amplia as desigualdades no Brasil.

\section{DESAFIOS BRASILEIROS: DESENVOLVIMENTO ECONÔMICO E SOCIAL}

Sobre a necessidade de desenvolvimento do Brasil, BRESSER PEREIRA (2018, p. 9) afirma:

“...o Brasil precisa dramaticamente de um projeto nacional; precisa vencer a quase estagnação econômica que já dura quase 40 anos, precisa se reindustrializar ou voltar a se sofisticar produtivamente, e precisa no plano político, recuperar a relativa coesão social perdida nos últimos cinco anos. Entre 1930 e 1980 o Brasil se industrializou e a renda per capita brasileira cresceu a uma taxa per capita de 3,8 ao ano; desde os anos 80 , o país entrou em desindustrialização e a economia está quase-estagnada, crescendo à modesta taxa de $1 \%$ até 2016, magnitude insuficiente para que o Brasil 
possa alcançar o nível de renda per capita dos países ricos. O Brasil está ficando para trás no conjunto dos Estados-nação e precisamos reverter isso."

Há vários desafios que precisam ser enfrentados no Brasil. Embora não haja aqui terremotos, vulcões ativos, maremotos, furacões ou outros exemplos de desastre naturais, ou mesmo conflitos declarados, e ainda sejamos beneficiados no nosso território com vastas terras produtivas e com amplos recursos naturais, nós brasileiros não fomos capazes ainda de construir uma sociedade menos desigual que permita acesso integral a sua população dos direitos sociais básicos.

Ao se falar no desenvolvimento nacional, são apontados diversos desafios que precisam ser superados. É comum a menção a melhoria da infraestrutura, a necessidade de pesquisa e inovação tecnológica, aprimorar as políticas de educação, promover a inclusão social e regional, racionalização dos gatos públicos, estabilidade econômica, etc. (análise de contas do Tribunal de contas da União apud NARDES et al., 2016, p. 63 ).

Os equívocos brasileiros ficam mais nítidos quando há comparação com outros países como Japão, Coreia do Sul e Israel, por exemplo, que com muito menos riquezas naturais, conseguem, todavia, oferecer aos seus cidadãos condições bem superiores de vida. Afinal, de que vale ser abundante em recursos naturais, ser rico, se a grande maioria da população brasileira não pode usufruir das riquezas de seu país?

No Brasil é possível que haja regiões na mesma época do ano com secas e outras inundadas, em virtude de chuvas e do descaso na ocupação territorial, seja ao desrespeitar as margens dos rios, seja a não haver a devida coleta do lixo, o que ocasiona o não escoamento das águas e inundação. Ademais, reforça o que foi aludido, a recente crise que se deu entre São Paulo e Rio de Janeiro no que tange a água. O Estado de São Paulo apresentou projeto de retirada de água de uma represa na bacia do rio Paraíba do Sul, no Vale do Paraíba, para suprir o Sistema Cantareira - maior fonte de abastecimento para a Grande São Paulo, afirmando que não iria prejudicar o Rio de Janeiro. Já o Estado fluminense preocupava-se com a possibilidade de desabastecimento das residências e das empresas, caso tal medida fosse autorizada pela Agência Nacional de Águas (ANA), conforme reportagem veiculada pela Agência Estado denominada: "Cabral e Alckmin já divergem sobre as águas do Rio Paraíba do Sul”.

Vale esclarecer que segundo reportagem do G1, a SABESP, concessionária pública responsável pelo abastecimento de água e a coleta de esgoto no Estado de São Paulo, desperdiça cerca de $30 \%$ da água tratada, isto evidencia a ineficiência da aludida empresa em tratar dos 
recursos hídricos, um verdadeiro absurdo para quem passa por uma seca. Surpresa maior ainda é constatar que a concessionaria pública fluminense consegue superar em ineficiência a sua coirmã paulista, visto que de acordo com reportagem do Jornal o Globo a CEDAE desperdiça cerca de 50\% de sua água, conforme reportagem: "Perdas na rede de água da Cedae chegam a $50 \%$ ". Tal desperdício representa um verdadeiro luxo, bem como total desrespeito aos que carecem de tão importante recurso natural. Caso as perdas de água nos supracitados Estados estivessem em patamares razoáveis, é provável que não tivesse ocorrido qualquer disputa quanto às águas do Paraíba do Sul.

Cumpre salientar que no Brasil sempre há um "culpado" pela falta de planejamento, As desculpas são variadas, tais como: crises econômicas mundiais imprevistas, "heranças malditas" e outros. Ultimamente, quem tem levado a culpa por parte dos administradores públicos é São Pedro. Caso não chova há crise energética por causa da seca nos reservatórios; se chove com intensidade, os alagamentos são recorrentes e ocorrem principalmente nos períodos de verão, ocasionando mortes, porque decorreram, segundo as autoridades, de chuvas de intensidade "imprevisíveis". Brinca-se a todo o momento com a vida humana, principalmente a do mais pobre, cujas habitações populares, em comunidades, estão mais sujeitas a serem atingidas e derrubadas devido às intempéries.

Frisa-se que há inúmeros outros casos de ineficiência brasileira, seja por incompetência ou mesmo por corrupção. Estradas não manutenidas e esburacadas ocasionando acidentes; portos com esgotamento, necessitando ser modernizados; o privilégio para o transporte rodoviário, em detrimento do ferroviário e hidroviário; pouco investimento na produção de energias, principalmente as renováveis, o que ocasiona crises periódicas, como ocorreu nos governos Fernando Henrique e Dilma Rousseff; mobilidade urbana, carecendo de investimentos e outros. Tais problemas evidenciam a necessidade de investimentos urgentes na infraestrutura brasileira para o crescimento da economia, geração de empregos e desenvolvimento do país.

A melhora da qualidade do sistema educacional brasileiro é outro desafio a ser enfrentado. A educação brasileira merece destaque a parte, haja vista estar relacionada tanto ao desenvolvimento do Brasil, com o desenvolvimento individual, bem como a diminuição das desigualdades. BRESSER- PEREIRA (2018, p. 83) explica:

O fator determinante do crescimento é o investimento, mas este só resultará em aumento da produtividade se a mão de obra que é necessária para operar as máquinas e coordenar a produção estiver disponível. Todos os países que se desenvolveram rapidamente deram prioridade à educação - a radical extinção do analfabetismo. Não 
foi assim no Brasil. O desempenho do Estado e das elites brasileiras em relação à educação é lamentável.

A educação é deficiente na maioria da rede pública de ensino do Brasil. Não se ensina as operações matemáticas básicas, tampouco se instrui a interpretar e raciocinar sobre um texto. $^{2}{ }^{3}$. NARDES et al $(2016$, p. 103) aponta medidas na educação para que o Brasil se desenvolva:

1. Condições para o ensino de toda sua população, sob os aspectos quantitativo e qualitativo;

2. Cultura voltada à inovação e ao desenvolvimento da tecnologia;

3. Condições propícias à retenção de valores humanos no país, em face de o conhecimento estar no rol dos recursos móveis;

4. Mecanismos de incentivo à produção de tecnologia, seja por linha de empréstimo ou de incentivos fiscais

Em 1905, Manuel Bonfim já apontava os problemas educacionais brasileiros no seu livro: "A América Latina: males de origem”. Assim, é preciso frisar que os problemas educacionais do Brasil têm cunho histórico e persistem devido à mentalidade da classe dirigente brasileira de que não se devia educar a classe pobre, com o objetivo de mantê-la sobre controle, atuando como parasita como defende o autor no seu aludido livro. Tal mentalidade não vigorou nos Estados Unidos da América como aponta BONFIM (2008, p. 138):

E é disto - do trabalho inteligente, da perfeição de processos - que depende a riqueza; só há um caminho para chegar lá: a cultura da inteligência, a difusão da instrução, a propagação da ciência. Voltem-se para os Estados Unidos, vejam como a indústria e a lavoura aproveitam ali o progresso da ciência. Tudo que a física, a química, a botânica, a meteorologia... ensinam tem uma aplicação imediata às indústrias. Vejam o esmero com que se instruem as massas populares e reconhecerão, então, que não foi a emigração quem produziu o maravilhoso progresso da grande república, mas a cultura, a instrução generalizada.

2 Este autor cursou o antigo primeiro e segundo grau (ensino fundamental e médio) em instituições públicas municipal e estadual da cidade do Rio de Janeiro, respectivamente. Devido à deficiência e baixa qualidade nesse ensino que, por exemplo, não foi capaz de lhe ensinar o conteúdo de física previsto para ensino médio, limitando-se a ensinar ao longo de três anos que Massa correspondia a aceleração multiplicada pela força. Outro exemplo, que também se passou com o autor, há cerca de 20 anos quando o autor cursou o $2^{\circ}$ grau e se preparava para o vestibular, um professor muito diligente com conteúdo da matéria que lecionava (química) afirmou em sala aos alunos que se ele dissessem que estava dando aquele conteúdo avançado em uma escola pública, outros professores não acreditariam. Este autor posteriormente financiou o seu desenvolvimento educacional, tão logo obteve remuneração para isso ao ingressar nas Forças Armadas.

3 Esse quadro vem piorando com o passar do tempo, nos colégios públicos, ao menos é o que este autor entende quando conversa com professores da rede pública de ensino.

Rev. de Direito Administrativo e Gestão Pública | e-ISSN: 2526-0073 | Porto Alegre | v. 4 | n. 2 | p. 117-136 | Jul/Dez. 2018 
BONFIM (2008, p. 139) critica a classe dirigente brasileira ao não educar o povo:

\begin{abstract}
Dir-se-ia que tais homens são incapazes de acompanhar os fenômenos sociais até a sua origem, e por isto pretendem colher os frutos, sem preparar a sementeira; constroem à chinesa: apuram a educação superior, antes de propagar a primária - fazem doutores para boiar sobre uma onda de analfabetos. Em vez do ensino popular, que prepare a massa geral da população - elemento essencial numa democracia, em vez da instrução profissional-industrial, donde tem saído o progresso econômico de todas as nações, hoje ricas e prosperas - em vez disto, reclama-se universidades - já alemãs, já francesas ${ }^{4}$.
\end{abstract}

Grifo Nosso

BONFIM (2008, p. 124 e 125) enfatiza que ao se libertar os escravos ninguém se deteve a examinar o caso e fazer a transformação na produção, não viam que o trabalho livre deve ser inteligente e aperfeiçoado e que era necessário educar o trabalhador, instruí-lo, levar o produtor a melhorar os seus processos, meio único de compensar a barateza do trabalho escravo. Ao contrário, impinge-se aos antigos escravos a obrigação por lei a trabalhar, por salário miserável, ao prescrever legalmente a vagabundagem. Ressalta ainda, o que é perceptível ainda nos dias atuais: "E o fazendeiro, que viveu sempre parasita, já não quer somente os braços barato; reclama também quotas diretas, em espécie - auxílios á lavoura, compensação aos lucros cessantes... ontem parasita do escravo, hoje parasita do Estado - é-lhe indiferente, certamente, quem o tenha de manter, contato que não haja de alterar o viver”.

Outrossim, BRESSER-PEREIRA (2018, p. 11) ensina que: "Para que a nação volte a ser viva e atuante é preciso que volte a ter um projeto, e para isto são necessárias ações políticas em muitos setores". Portanto, extrai-se dessa lição a necessidade do Brasil ser repensado, da formulação de um projeto de desenvolvimento que enfrente os desafios neste estudo aludidos e ainda outros, se de fato almeja-se proporcionar uma vida melhor aos seus cidadãos brasileiros.

\title{
4. DESIGUALDADE E DISTRIBUIÇÃO DE RENDA
}

A desigualdade é tratada por ROUSSEAU (2017, p. 43) que explica:

Concebo na espécie humana dois tipos de desigualdade: uma que chamo natural ou física, porque é estabelecida pela natureza e consiste na diferença das idades, da saúde, das forças do corpo e das qualidades do espírito ou da alma; outra que podemos

Manuel Bonfim critica a ideia de transportar para o Brasil as universidades germânicas para solução dos problemas educacionais.

Rev. de Direito Administrativo e Gestão Pública | e-ISSN: 2526-0073 | Porto Alegre | v. 4 | n. 2 | p. 117-136 | Jul/Dez. 2018 
chamar de desigualdade moral ou política, porque depende de uma espécie de convenção e é estabelecida, ou pelo menos autorizada, pelo consentimento dos homens. Esta consiste nos diferentes privilégios que alguns usufruem em detrimento dos outros, como o de serem mais ricos, mais honrados, mais poderosos que eles, ou mesmo o de fazerem obedecer por eles.

Cumpre explicar que as desigualdades extremas tendem a dificultar o crescimento econômico e minar a igualdade política e a estabilidade social, com efeitos cumulativos na economia, sociedade e política (STIGLITZ, 2016, p. 257).

Por sua vez, a Constituição Federal de 1988 é uma opção pelo Estado Democrático e Social. Tal premissa fica clara em diversos dispositivos. Para título de exemplo destaca-se o art. $3^{\circ}$ que trata dos objetivos fundamentais:

Art. $3^{\circ}$ Constituem objetivos fundamentais da República Federativa do Brasil:

I - construir uma sociedade livre, justa e solidária;

II - garantir o desenvolvimento nacional;

III - erradicar a pobreza e a marginalização e reduzir as desigualdades sociais e regionais;

IV - promover o bem de todos, sem preconceitos de origem, raça, sexo, cor, idade e quaisquer outras formas de discriminação.

Desse modo, a interpretação mais adequada do texto constitucional é no sentido de que políticas públicas governamentais devem estar de acordo com os objetivos elencados pela federação brasileira, isto é, a economia e a política devem ser conduzidas com as finalidades de redução das desigualdades, desenvolvimento do país, liberdade e justiça, promoção do bem das pessoas e extinção das formas de discriminação. A administração e seus representantes devem sempre trabalhar tendo como meta o cumprimento dos aludidos preceitos constitucionais. Aliás, corrobora esse entendimento de DA SILVA (2005, p. 46) ao explicar sobre os objetivos fundamentais:

Não significa que outros objetivos não devam constituir preocupação do Estado. Significa apenas que os objetivos fundamentais são impostergáveis e hão de ser preocupação constante da ação governamental, porque a Constituição entende que sua realização constitui meio de conseguir a realização plena dos fundamentos do Estado Democrático de Direito, enunciados no art. $1^{\circ}$.

Desta maneira, fica claro que a atuação governamental em sentido contrário a promoção dos supracitados objetivos fundamentais será inconstitucional. BERCOVICI (2006) observa que, na prática, embora expresso os objetivos fundamentais na Constituição, não se atua de modo a alcançá-los efetivamente, passando a ser interpretada e aplicada como se fosse meramente processual, "norma programática", com diretrizes e lógica próprias, separada 
totalmente da ordem econômica e social, esterilizando, assim, a capacidade de intervenção do Estado na economia.

BRESSER-PEREIRA (2018, p. 123-124) destaca que no grande acordo que foi a transição democrática, empresários e trabalhadores concordaram não apenas em torno da democracia, mas também da necessidade de reduzir a grande desigualdade econômica da sociedade brasileira, acordo este que passaria principalmente pelo aumento do gasto social do Estado em educação e saúde. Contudo, nada se falou sobre o imposto progressivo, apontado por Bresser como causa principal da desigualdade brasileira.

TORRES (2008, p. 61) observa sobre as escolhas da política fiscal e orçamentária brasileira:

Do lado da receita pública a imposição fiscal recaiu principalmente sobre as pessoas e as classes que denotavam menor capacidade contributiva: os assalariados e os consumidores finais de bens necessários à existência; a tributação de ganhos de capital e do consumo suntuário sempre foi tímida. Do lado da despesa pública investiu-se importância incalculável na intervenção direta na economia e na duvidosa política desenvolvimentista; concederam-se incentivos e subvenções a mancheias a empresários incompetentes e instituições assistenciais ineficientes; pouco se gastou comparavelmente em educação primária e a saúde pública. O resultado só poderia ser o que presenciamos: a mais injusta concentração de renda do Ocidente e uma das mais perversas migrações internas ocorridas no século passado. Faltou ética no orçamento, posto que tudo isso era jurídico, no sentido formal do termo, isto é, insuscetível de controle jurisdicional .

Cabe explicitar lição de STIGLITZ, (2016, p. 257-258) que desigualdades crescentes, com distribuição de renda desequilibradas, reduzem a demanda agregada (os ricos tendem a gastar uma proporção menor de sua renda, em comparação com os pobres) e isso pode tornar o crescimento econômico mais lento. A tentativa das autoridades monetárias de compensar esses efeitos pode contribuir para a formação de bolhas de crédito, e essa bolhas, por sua vez, provocam estabilidade econômica É por isso que a desigualdade frequentemente está associada à instabilidade econômica.

Merece destaque que melhoria dos indicadores sociais brasileiros exige o investimento adequado em políticas públicas sociais de transferência de renda dos ricos para os pobres e ainda de uma política educacional consistente que permita ampla concorrência e acesso empregos e cargos mais qualificados, com maior remuneração, de modo que se promova ascensão ao em vez da extratificação social, característico de um sistema castal. Ensina STIGLITZ, (2016, p. 258) sobre os efeitos maléficos da desigualdade na economia e a importância da sua redução para o desenvolvimento: 
Boa parte das desigualdade observada no mundo todo está associada à caça à renda (por exemplo, o exercício do poder monopolista), e essa desigualdade claramente ataca a eficiência econômica. Contudo talvez a pior dimensão da desigualdade seja a de oportunidade, que é a causa e consequência da desigualdade de resultados e provoca ineficiência econômica e redução do desenvolvimento, já que um grande número de pessoas não tem condições de desenvolver seu potencial. Países com alta desigualdade tendem a investir menos em bens públicos, como infraestrutura, tecnologia e educação fatores que contribuem para o crescimento e a prosperidade econômica no longo prazo.

Outrossim, STIGLITZ, (2016, p. 258) aponta ainda os benefícios da diminuição da desigualdade que traz evidentes benefícios econômicos e sociais. Fortalece o senso de que a sociedade é justa; melhora a coesão e mobilidade social, aumentando a probabilidade de que mais cidadãos desenvolvam seu potencial e amplia o apoio a iniciativas de crescimento. Assim, as políticas que buscam crescimento, mas ignoram a desigualdade podem ser, em última análise, contraproducentes. Ao passo que as políticas que diminuem - por exemplo, estimulando emprego e a educação - provocam efeitos benéficos sobre o capital humano, cada vez mais necessário para as economias modernas.

Por oportuno, o caminho da boa administração pública passa por melhor eficiência, maior controle e diminuição da corrupção, voltadas principalmente para redução das desigualdades sociais brasileiras. A diminuição das desigualdades pode trazer efeitos benéficos à economia e ao desenvolvimento de um país, como observa esta pesquisa.

\section{CONSIDERAÇÕES FINAIS}

Este estudo aponta que o caminho para o desenvolvimento do Brasil passa por desempenho melhor na administração pública, que compreenda medidas para uma gestão pública mais eficiente, menos corrupta, bem como pela diminuição das desigualdades sociais, por meio de políticas publicas de distribuição de renda.

Desse modo, são necessárias a adoção de medidas que privilegiem a boa gestão dos recursos públicos. Nessa denominada boa gestão está inclusa o atendimento dos objetivos sociais expressos na Constituição Federal de 1988: construir uma sociedade livre, justa e solidária; garantir o desenvolvimento nacional; erradicar a pobreza e a marginalização e reduzir as desigualdades sociais e regionais; promover o bem de todos, sem preconceitos de origem, raça, sexo, cor, idade e quaisquer outras formas de discriminação. Não é possível administrar 
bem o Brasil, sem observar os preceitos Constitucionais que estabelecem o desenvolvimento dos cidadãos brasileiros, seja individualmente, seja no conjunto da sociedade.

Por sua vez, para que o almejado desenvolvimento seja alcançado, trazendo com isso benefícios sociais, este estudo destacou que são precisos planejamento e controle das ações desempenhadas pelos administradores públicos. Assim, são necessárias políticas públicas contínuas, consistentes e criteriosas - de curto, médio e longo prazos - voltadas para resultado eficiente, bem como o investimento probo dos recursos públicos.

$\mathrm{O}$ direito à boa administração foi frisado como fundamental e como premissa da vida melhor para cidadãos brasileiros. Há vários equívocos a se corrigir nesse ramo e este trabalho apontou alguns destes.

Esta pesquisa defendeu que para se alcançar o desenvolvimento no Brasil é imprescindível se combater de forma simultânea e contínua; a ineficiência, a corrupção e a desigualdade. O debate jurídico nacional sobre a necessidade de formulação de políticas públicas que privilegiem a boa administração pública e que realmente considerem esta como um direito fundamental dos indivíduos é importante para o avanço nessa área.

\section{REFERÊNCIAS}

AGÊNCIA ESTADO. Cabral e Alckmin já divergem sobre as águas do Rio Paraíba do Sul. Disponível em: $\quad<$ http://www.huffpostbrasil.com/2014/03/20/transposicao-rioparaiba_n_5001335.html>Acesso em 27 de novembro de 2017.

BRASIL, Constituição da República Federativa do Brasil de 1988, de 05 de outubro de 1988. In: Senado Federal. Legislação Republicana Brasileira. Brasília, 2017. Disponível em: < http://www.planalto.gov.br/ccivil_03/constituicao/constituicao.htm> Acesso em: 24 jun. 2017.

BERCOVICI, Gilberto; Massonetto, Luís Fernando. A constituição dirigente invertida: a blindagem da Constituição Financeira e a agonia da Constituição Econômica. Disponível em <http://hdl.handle.net/10316.2/24845> Acesso em 22 nov. 2017.

BONAVIDES, Paulo. Curso de direito constitucional. 31 ed. São Paulo: Malheiros Editores, 2016.

BONFIM, Manuel. América Latina: males de origem. Rio de Janeiro: Topbooks, 1993.

BRESSER-PEREIRA, Luiz Carlos. Em busca do Desenvolvimento perdido: um projeto de novo-desenvolvimentista do Brasil. Rio de Janeiro: FGV Editora, 2018.

DA SILVA, José Afonso. Comentário contextual à Constituição. São Paulo: Malheiros, 2005. 
Curso de direito constitucional positivo. 11 ed São Paulo: Malheiros, 2005.

DUARTE, Hélter. Mensagens de celular ligam Pezão ao esquema de corrupção de Cabral. Disponível em: <http://g1.globo.com/jornal-hoje/noticia/2017/06/mensagens-de-celularligam-pezao-ao-esquema-de-corrupcao-de-cabral.html> Acesso em 28 de novembro de 2017.

FIGUEIREDO, Marcus e FIGUEIREDO, Argelina C. "Avaliação Política e Avaliação de Políticas: Um Quadro de Referência Teórica", Revista Fundação João Pinheiro: 108-129. 1986.

Folha de São Paulo. Desigualdade de renda no Brasil não caiu entre 2001 e 2015, aponta estudo. Disponível em: $<$ http://www1.folha.uol.com.br/mercado/2017/09/1916858desigualdade-no-brasil-nao-caiu-desde-2001-aponta-estudo.shtml $>$ Acesso em 27 de novembro de 2017

G1. Sabesp desperdiça 30\% da água tratada. Disponível em: $<$ https://g1.globo.com/saopaulo/noticia/sabesp-desperdica-30-da-agua-tratada.ghtml> Acesso em 27 de novembro de 2017.

GARCIA, Emerson e ALVES, Rogério Pacheco. Improbidade Administrativa. 4 ed. Rio de Janeiro: Lumen Juris, 2008.

HEIDEMANN, Francisco G. Do sonho do progresso às políticas de desenvolvimento. In HEIDEMANN, Francisco G; SALM, José Francisco (org). Políticas públicas e desenvolvimento. Bases epistemológicas e modelos de análise. 3. ed. Brasília: Editora Universidade de Brasília, 2014.

HOCHMAN, Gilberto et al. Políticas Públicas no Brasil. Rio de Janeiro: Fiocruz, 2007.

MÁXIMO, Wellton. Desigualdade de renda no Brasil não caiu entre 2001 e 2015, revela estudo. Disponível em: <http://agenciabrasil.ebc.com.br/economia/noticia/201709/desigualdade-de-renda-no-brasil-nao-caiu-entre-2001-e-2015-revela-estudo > Acesso em 27 de novembro de 2017.

MOREIRA NETO, Diogo de Figueiredo. Mutações do Direito Administrativo. 3. ed. Rio de Janeiro: Renovar, 2007.

O Globo. Perdas na rede de água da Cedae chegam a $\mathbf{5 0 \%}$. Disponível em: https://oglobo.globo.com/rio/perdas-na-rede-de-agua-da-cedae-chegam-50-9311882> Acesso em 27 de novembro de 2017.

QUARTZ. More than half the lawmakers impeaching Brazil's president have been either convicted or investigated themselves. Disponível em < https://qz.com/770206/more-than-halfthe-lawmakers-impeaching-brazils-president-have-been-either-convicted-or-investigatedthemselves/> Acesso em 28 de novembro de 2017.

SALVADOR, Evilasio. Fundo público e políticas sociais na crise do capitalismo. Serv. Soc. Soc., São Paulo, n. 104, p. 605-631, out./dez. 2010. 
SOUZA, Celina. Estado da arte da pesquisa em políticas públicas. In HOCHMAN, Gilberto et al. Políticas Públicas no Brasil. Rio de Janeiro: Fiocruz, 2007.

TORRES, Ricardo Lobo. Tratado de direito constitucional financeiro e tributário Volume II - valores e princípios constitucionais tributários. Rio de Janeiro: Renovar: 2005.

Tratado de direito constitucional financeiro e tributário Volume V orçamento na Constituição. Rio de Janeiro: Renovar: 2008. 